\title{
Improvement of Sorghum (Sorghum bicolor l. Moench) Growth and Yield under Drought Stress by Inoculation with Bacillus cereus and Foliar Application of Potassium Silicate
}

\author{
Maged M. Abdul Halim Saad ${ }^{1}$ and Hanaa A. Abo-Koura ${ }^{2 *}$ \\ ${ }^{1}$ Agriculture Genetic Engineering Research Institute, Agriculture Research Center, \\ Giza, Egypt. \\ ${ }^{2}$ Soils, Water and Environment Research Institute, Agricultural Research Center, \\ Giza, Egypt.
}

$\mathbf{T}$

EN plant growth promoting rhizobacteria (PGPRs) isolated from the rhizosphere of sorghum plants were screened for production of Indole acetic acid (IAA), exopolysaccharide (EPS), phosphate solubilizing, siderophore production and Hydrogen cyanide (HCN), in addition to the ability to withstand drought and heat stresses. The best performing isolate was identified by both biochemical and molecular methods as Bacillus with $99 \%$ similarity to B. cereus strain. The in vivo plant growth promoting activity of identified strain on Sorghum growth (Sorghum bicolor l. Moench) under drought stress was evaluated at a field experiment in combination with different levels of potassium silicate. Treatments included inoculation of seeds by B. cereus and three levels of K silicate (50.150 and 200 ppm) as foliar spray. Drought stress was achieved by spacing between irrigation times ( 20 days between each irrigation). Results showed that, supplementation of $\mathrm{K}$ silicate $(50,150$ and $200 \mathrm{ppm})$ plus PGPRs inoculation increased vegetative growth, $\mathrm{RWC} \%$ and improved electrolyte leakage, recorded $76.2 \%, 82.2 \%$ and $80.2 \%$ respectively. Proline content recorded $23.6 \%, 32.1 \%$ and $34.14 \%$ respectively under deficit water. As well as the combined treatment between inoculation and $\mathrm{K}$ silicate improved photosynthetic pigments, chlorophyll stability index, osmotic potential, plant $\mathrm{K}^{+}, \mathrm{Ca}^{2+}$ and $\mathrm{Mg}^{2+}$ accumulation, while reduced $\mathrm{Na}^{+}$uptake besides that enhanced $\mathrm{Na} / \mathrm{K}$ ratio compared to control under drought. Also, K silicate only or with PGPRs bacteria increased the total number of bacteria and actinomycetes in rhizosphere but reduced the number of soil fungi. Antioxidant enzymes were reduced affected by the combined action of inoculation with $B$. cereus and $\mathrm{K}$ silicate spraying. The results proved that the combination of PGPRs plus foliar application of $\mathrm{K}$ silicate is favorable treatment under drought stress.

Keywords: Sorghum plant, Photosynthetic pigments, Proline, Osmotic potential, Yield and Drought Tolerance Index.

\section{Introduction}

Sorghum (Sorghum bicolor L.) is considering the fourth in a space as a cereal crop, after wheat, maize and rice In Egypt, also it grows well under environmental stresses such as drought (Mekdad and Rady 2016). Most of countries depend on them to obtain grains from it, like Nigeria, USA and India, while Egypt has ranked fifteen in this respect (FAO, 2012). Sorghum (Sorghum bicolor L.Moench) is a located under family Poaceae. Sorghum is considered very important annual cereal crop grown for obtaining grain and palatable green forage production. Sorghum can be grown in many arid and semi-arid regions of the world, due to its advantages over (Marsalis et al. 2010). Abdel-Motagally (2010) cleared that sorghum is used in a double purpose; the first purpose to vegetative parts in feeding the animal in summer season, and the other purpose to obtain grains. Drought reduces nutrient uptake by inducing nutrient deficiency by decreasing the rate of nutrients from soil to root (Ashraf and Foolad 2007). Plants can be able to tolerance to drought conditions by accumulating with Proline. Proline(a non-protein amino acid formed in the leaf tissues of plants exposed to water stress) accumulation and increased ant oxidative enzymes such as peroxidase.

*Corresponding author e-mail: Lana_allah333@yahoo.com DOI:10.21608/JENVBS.2019.6790.1045 
Silicon is second most element in the Earth's (Ma et al. 2006), it plays an important role in plant tolerance to environmental stresses (Gong et al. 2005; Gunes et al. 2007a, 2008). It is reported that, $\mathrm{Si}$ is one of the greater tolerance of higher plants to drought stress. It increases the action of antioxidant defenses; also it can be reduced the oxidative damage to functional molecules and membranes, (Agarie et al. 1998). Gong et al. (2003) reported that $\mathrm{Si}$ able to decrease the specific leaf area in wheat and have also been suggested to be involved in the inhibition of leaf water deficit.

PGPRsbacteria is a large group of bacteria which able to colonizes the rhizosphere of soil plants and interact with it, helping the plant to grow in both direct and indirect ways (Kloepper 1999). It can be able to protect plants from the deleterious effects of some environmental stresses (Marulanda et al. 2008), also induced systemic tolerance (IST) and induced physical and chemical changes that result in enhanced tolerance of plants to abiotic stress (Yang et al. 2009). Under drought stress, bacterial can accumulate compatible solutes such as amino acids, quaternary amines, and sugars that may prevent degenerative processes and improves cell growth under adverse osmotic conditions (Potts 1994). In this study, the effect of PGPRs (MSR H1) inoculation plus concentration of $\mathrm{K}$ silicate on some characteristics of sorghum has been investigated under water deficit stress.

\section{Materials and Methods}

\section{Isolation and characterization of bacteria}

Bacteria were isolated from the rhizosphere soils of sorghum plants collected from different localities of Agricultural Research Center (ARC) farm (Giza Governorate, Egypt) using serial dilution technique on nutrient agar plats at $28 \pm 2^{\circ} \mathrm{C}$ for 72 hrs. Morphologically different colonies were picked and subjected to further purification then stored on nutrient agar slants at $4^{\circ} \mathrm{C}$.

\section{Bacterial characteristics}

BGPRs bacterial isolates are checked to Morphological characteristics, like shape and gram reaction as described by Bergey's manual of determinative bacteriology (Holt et al.1994) and to motility by hanging drop methods as described by Bertand et al. (2001). The bacterial isolates were coded from (H1-H10).

\section{Screening of isolates for plant growth-promoting potential}

The bacterial isolates were screened for gram reaction and plant growth-promoting activities such as, IAA (Indole acetic acid) production, as described by Sarwar et al. (1992). Exopolysaccharides synthesis was determined using the method described by Ashraf et al. (2004). Siderophores production was tested to all isolates according to Schwyn and Neilands (1987). The solubilized phosphates were described by methods of Mehta and Nautiya (2001). Production of cyanide $(\mathrm{HCN})$ was measured as described by Bakker and Schippers (1987). According to the previous tests, ten isolates were selected for drought and heat tolerance assay.

\section{Drought Tolerance Assay for selected isolates}

Test tubes containing seven $\mathrm{ml}$ sterilized nutrient broth supplemented with different concentration of polyethylene glycol (PEG6000) $0,10,20,30 \%$ were inoculated with $0.5 \mathrm{ml}$ of $24 \mathrm{~h}$ old culture of each isolate then incubated at $28 \pm 1{ }^{\circ} \mathrm{C}$ for $96 \mathrm{~h}$ in three replicates, at the end of incubation period, optical density for all isolates was measured by spectrophotometer at $600 \mathrm{~nm}$.

\section{Thermo tolerance assay}

Isolates were streaked on nutrient agar plates and incubated at different temperatures (30, 45 and $50^{\circ} \mathrm{C}$ ) for $48 \mathrm{~h}$, at the end of incubation period; plates were investigated for positive or negative growth.

Identification of the most potent bacterial isolate

According to drought and heat tolerance assay one bacterial isolate was identified by $16 \mathrm{~S}$ rRNA gene sequencing, using PCR master mix (Promega, Madison, WI, USA) with bacterial universal primer sets $27 \mathrm{~F}$ and 1492R (27F: 5'AGA GTT TGA TCC TGG CTC AG-3' and 1492R: 5'-TACGGYTACCTT GTTACGACT T-3'). Resolved 16S rRNA gene sequences were BLAST searched against the National Center for Biotechnology Information (NCBI) (http:// www.ncbi.nlm.nih.gov) database (Altschul et al., 1997). Multiple alignments of the nucleotide sequences were performed with the program MUSCLE (Edgar 2004). The phylogenetic tree was constructed by the Neighbor-Joining method (Saitou and Nei 1987), based on the Kimura 2-parameter model (Kimura 1980), with bootstrap analysis (1,000 replications) using the software MEGA (version 7) (Kumar et al. 2016).

Evaluation of Bacillus cereus strain MSR-H1 for growth of sorghum in field trail under drought stress

During $2016 / 2017$ at Giza Research 
Experimental Station, ARC, Giza Govern., Egypt (latitude of $29^{\circ} 26^{\prime} \mathrm{N}$ and longitude of $31^{\circ} 13^{\prime} \mathrm{E}$ ) a field experiment was designed to evaluate the potential of $B$. cereus in alleviation of drought stress on sorghum plant. The treatments included combinations between inoculation with $B$. cereus and spraying with different concentrations of potassium silicate $\left(\mathrm{K}_{2} \mathrm{SiO}_{3}, 99 \%\right.$ purity) as follow: T1: control under normal irrigation,

T2: control under drought stress,

T3: plants under drought sprayed with 50ppm K-Si solution,

T4: plants under drought sprayed with $150 \mathrm{ppm}$ K-Si solution

T5: plants under drought sprayed with 200ppm K-Si solution,

T6: plants under drought inoculated with $B$. cereus,

T7: plants under drought inoculated with $B$. cereus and sprayed with 50ppm K-Si solution,

T8: plants under drought inoculated with $B$. cereus and sprayed with 150ppm K-Si solution,

T9: plants under drought inoculated with $B$. cereus and sprayed with 200ppm K-Si solution. Drought stress was achieved by irrigating the plants every 20 days. The recommended doses of the chemical fertilizer (NPK) were used according to the recommendation of Agriculture and Land Reclamation, Egypt. Experimental treatments were laid out in a randomized complete block design (RCBD) with four replications, the plot area was $6 \mathrm{~m}^{2}$ (sub-plot sizes $2 \times 3 \mathrm{~m}$ ) $=1 / 400$ feddan (feddan $=4200 \mathrm{~m}^{2}$ ). Each plot included 3 rows with 30 $\mathrm{cm}$ row spacing.

Soil physicochemical properties were analysis according to Blake (1982).

\section{Inoculation technique}

drought - sensitive sorghum seeds (Shandaweel-1) (Sorghum bicolor L. Moench) obtained from field Crops Research Inst., (ARC), Giza, Egypt were inoculated with B. cereus $\left(10^{9}\right.$ $\mathrm{CFU} / \mathrm{ml}$ ) carried on vermiculite carrier using Arabic gum as adhesive agent.

\section{Data collection}

Vegetative growth characteristics: Sample of 10 plants were randomly taken at physiological maturity from two internal rows after 45 and 75 days to measure, Leaf dry weight (LDW), shoot dry weight (SDW), root dry weight (RDW), total dry weight (TDW) and Shoot/Root ratio (R/S).

\section{Relative water content (RWC\%)}

To evaluate the water status during the stress period, relative water content RWC was used, according to the equation described by Kaya and Higgs (2003) Cut leaves were weighed (fresh weight, FW), then left saturated in water for three hours and their turgid weights (TW) were calculated. The samples were then dried in an oven at $80^{\circ} \mathrm{C}$ for 24 hours and weighed (ODW). The RWC is determined as follows:

$\mathrm{RWC}(\%)=[(\mathrm{FW}-\mathrm{ODW}) /(\mathrm{TW}-\mathrm{ODW}] \times 100$

Electrolyte leakage (\%)

Electrolyte leakage was determined according to protocol as described by Awad et al. (2006).

Photosynthetic pigments and Proline
determination

Photosynthetic pigments(chlorophyll a,b, Total chlorophyll and carotenoid's) were measured and calculated as described by Nornai (1982) as well as the proline content was determined according to Bates et al. (1973)

\section{Chlorophyll stability index}

The (CSI) was determined according to protocol as described by Sairam et al. (1997):

$$
\begin{gathered}
\mathrm{CSI}=(\text { Total } \mathrm{Chl} \text { under stress } / \text { Total } \mathrm{Chl} \text { under } \\
\text { control }) \times 100
\end{gathered}
$$

\section{Microbial populations}

The total bacteria and fungi count in rhizosphere soil after 45 and 75 days from planting were determined using nutrient agar media (Difco 1985) and Martin (1951) for fungi count respectively. Total actinomycetes were determined as described by Rolf and Bakken (1987). Silicate bacteria were also determined according to Zahra (1969).

\section{Antioxidant Enzymes Assays}

Antioxidant Enzymes like: Catalase (CAT) enzyme was determined according to the method of Aebi (1983). Ascorbate Peroxidase (APX) was determined according to Nakano and Asada (1981). Super Oxide Dismutase (SOD) was determined according to Donahue et al (1997).

\section{Osmotic potential in leaves of plants}

The osmotic potential leaves were measured from flag leaves according to the method of Capell and Doerffling (1993).

\section{Biochemical constituents}

Total nitrogen and total phosphorus in shoots were determined according to Black (1982). Ions like $\mathrm{K}^{+}, \mathrm{Na},{ }^{+} \mathrm{Mg}^{2+}$ and $\mathrm{Ca}^{2+}$ determantion according to Wolf, (1982). The initial $\mathrm{pH}$ of the soil was measured after adding potassium silicate using benchtop $\mathrm{pH}$ meter (Orion 2-Star; Thermo Scientific, USA), as described by (Margesin and Schinner 2005).

Env. Biodiv. Soil Security Vol. 2 (2018) 


\section{Yield parameters}

Five representative guarded plants were taken from each Plot to determine, plant height $(\mathrm{cm})$, grain panicle, grain yield, 100 grains weight and Biological yield were also determined.

Drought Tolerance Index

Drought or stress tolerance index of the sorghum was calculated as protocol described by (Ahmad, 2011). Tolerance (TOL) and Yield stability index (YSI) were calculated using the following relationships Farshadfar and Sutka (2002)

$$
\mathrm{TOL}=\mathrm{Y}_{\mathrm{s}}-\mathrm{Y}_{\mathrm{p}}: \mathrm{YSI}=\mathrm{Y}_{\mathrm{s}} / \mathrm{Y}^{\mathrm{p}}
$$

In the above formulas, Ys, Yp, represent yield under stress, yield non-stress for cultivar.

Statistical analysis

Data were statistically analyzed by analysis of variance (ANOVA) using MSTATC program version 2.10 (1991). The least significance difference (LSD) test (0.05) was used to find out the significance of mean difference of various treatments (Gomez and Gomez, 1984).

\section{Results}

Soil physiochemical properties

Soil used was clay loam type with $33.4 \%$
Clay, silt $35.6 \%$, fine sand $19.6 \%$, and coarse sand11.2\%, with a $\mathrm{pH} 7.3$ and $\mathrm{EC} \mathrm{dS} \mathrm{m}^{-1} 2.6$. Soluble elements as cat ions and anions $\left(\mathrm{mg} \mathrm{L}^{-1}\right)$ as follows: for cations: $\mathrm{K}^{+}, \mathrm{Na}^{+}, \mathrm{Mg}^{++}$andCa ${ }^{++}$ were $1.52,8.16,6.67$ and 9.20 , respectively. Anions were $\mathrm{SO}_{4}^{-13.07,} \mathrm{Cl}^{-11.13}, \mathrm{HCO}^{3-} 1.35$, $\mathrm{CO}_{3}^{-} 0.00$

\section{Isolation of rhizobacteria}

A total of ten bacterial isolates obtained from the rhizosphere soil of sorghum plant using plate count technique on nutrient agar were screened for plant growth promoting activity (indole acetic acid, E.P.S production, phosphate solubilizing and siderophore production (Table 1). Higher IAA and exopolysaccharides production were noted for isolates $\mathrm{H} 1\left(16.4 \mathrm{mgL}^{-1}\right)$ and $(6.8 \mathrm{~g} / 100 \mathrm{ml})$ respectively, while isolate $\mathrm{H} 6$ gave lower IAA production and EPS production $\left(11.5 \mathrm{mgL}^{1}\right)$ and $(3.2 \mathrm{~g} / 100 \mathrm{ml})$. Isolates No (2.3.4 and 9) were not able to phosphate solubilizing in media while isolates No. $(1,4,5,6,7$ and 10) can able to phosphate solubilizing in media. All tested isolates were able to produce siderophores while in case of $\mathrm{HCN}$, isolates No (H6, H7, H10) gave negative results for the test.

TABLE 1. Characteristics of selected PGPRs bacteria for plant growth promoting activity.

\begin{tabular}{|c|c|c|c|c|c|c|}
\hline Isolates & $\begin{array}{c}\text { Gram } \\
\text { reaction }\end{array}$ & $\begin{array}{c}\text { Indole acetic } \\
\text { acid (IAA) } \\
\left(\text { mgL }^{-1}\right)\end{array}$ & $\begin{array}{c}\text { Exo } \\
\text { polysaccharides } \\
\text { (E.P.S) } \\
(\text { g/100 } \mathbf{~ m l}\end{array}$ & $\begin{array}{l}\text { phosphate } \\
\text { solubilizing }\end{array}$ & $\begin{array}{l}\text { Siderophore } \\
\text { production }\end{array}$ & $\begin{array}{c}\mathrm{HCN} \\
\text { production }\end{array}$ \\
\hline H 1 & + & 16.4 & 6.8 & + & + & ++ \\
\hline $\mathrm{H} 2$ & - & 13.2 & 5.9 & - & ++ & ++ \\
\hline $\mathrm{H} 3$ & + & 14.7 & 4.6 & - & + & + \\
\hline H 4 & - & 12.3 & 5.3 & + & + & + \\
\hline H 5 & + & 13.9 & 4.1 & + & ++ & + \\
\hline H 6 & - & 11.5 & 3.2 & + & + & - \\
\hline $\mathrm{H} 7$ & - & 13.1 & 4.2 & + & ++ & - \\
\hline $\mathrm{H} 8$ & + & 13.5 & 3.9 & - & + & + \\
\hline H 9 & - & 12.2 & 4.8 & - & + & + \\
\hline H 10 & - & 13.9 & 3.5 & + & + & - \\
\hline L.S.D at 0.05 & & n.s & n.s & & & \\
\hline
\end{tabular}

-- Negative growth, + positive growth, n.s non significant

Screening isolates for drought tolerant stress and thermo tolerance

Ten bacterial isolates screened for drought and heat tolerance (Table 2). All isolates were able to grow at different concentration of (PEG \%).
Isolates $\mathrm{H} 1$ showed the highest optical density followed by isolate $\mathrm{H} 5$ at PEG $10 \%$, while at 20\% PEGH 1, H 2 and $\mathrm{H} 8$ recorded the highest growth. At concentration 30\% from (PEG ) H1, $\mathrm{H} 3$ and $\mathrm{H} 5$ recorded highest growth while $\mathrm{H} 4$ 
recorded lowest growth.H1 was the most tolerant isolate among the others. Besides that, isolate $\mathrm{H} 1$ can grow at $45^{\circ} \mathrm{C}$ followed by isolates $\mathrm{H} 2$ and $\mathrm{H} 5$, whereas isolates $\mathrm{H} 4, \mathrm{H} 6, \mathrm{H} 8, \mathrm{H} 9$, and $\mathrm{H} 10$ cannot grow at $40^{\circ} \mathrm{C}$ and $45^{\circ} \mathrm{C}$.

\section{Identification of the most potent isolate}

According to previous results, isolate $\mathrm{H} 1$ was selected to complete the study and identified by16S rRNA sequences technique. Based on the $16 \mathrm{~S}$ phylogenetic classification, the isolate MSR

TABLE 2. Screening isolates for drought and heat stresses tolerance.

\begin{tabular}{|c|c|c|c|c|c|c|c|}
\hline \multirow{3}{*}{ Isolates } & \multicolumn{4}{|c|}{ Drought tolerant at (OD) $600 \mathrm{~nm}$} & \multicolumn{3}{|c|}{ Heat tolerance } \\
\hline & \multicolumn{4}{|c|}{ PEG \% } & \multicolumn{3}{|c|}{ Temperature } \\
\hline & $\mathbf{0}$ & 10 & 20 & 30 & $40^{\circ} \mathrm{C}$ & $45^{\circ} \mathrm{C}$ & $50^{0} \mathrm{C}$ \\
\hline $\mathrm{H} 1$ & 1.02 & 0.45 & 0.22 & 0.10 & + & + & - \\
\hline $\mathrm{H} 2$ & 0.80 & 0.39 & 0.20 & 0.08 & + & + & - \\
\hline $\mathrm{H} 3$ & 0.83 & 0.40 & 0.17 & 0.09 & + & - & \\
\hline $\mathrm{H} 4$ & 0.66 & 0.30 & 0.12 & 0.05 & - & - & - \\
\hline H5 & 0.70 & 0.42 & 0.19 & 0.09 & + & + & \\
\hline H6 & 0.44 & 0.25 & 0.17 & 0.08 & - & - & - \\
\hline H7 & 0.33 & 0.20 & 0.11 & 0.06 & + & - & \\
\hline H8 & 0.36 & 0.19 & 0.20 & 0.08 & - & - & - \\
\hline H9 & 0.44 & 0.30 & 0.12 & 0.07 & - & - & - \\
\hline H10 & 0.40 & 0.29 & 0.18 & 0.08 & - & - & - \\
\hline
\end{tabular}

+ Positive growth,- negative growth.

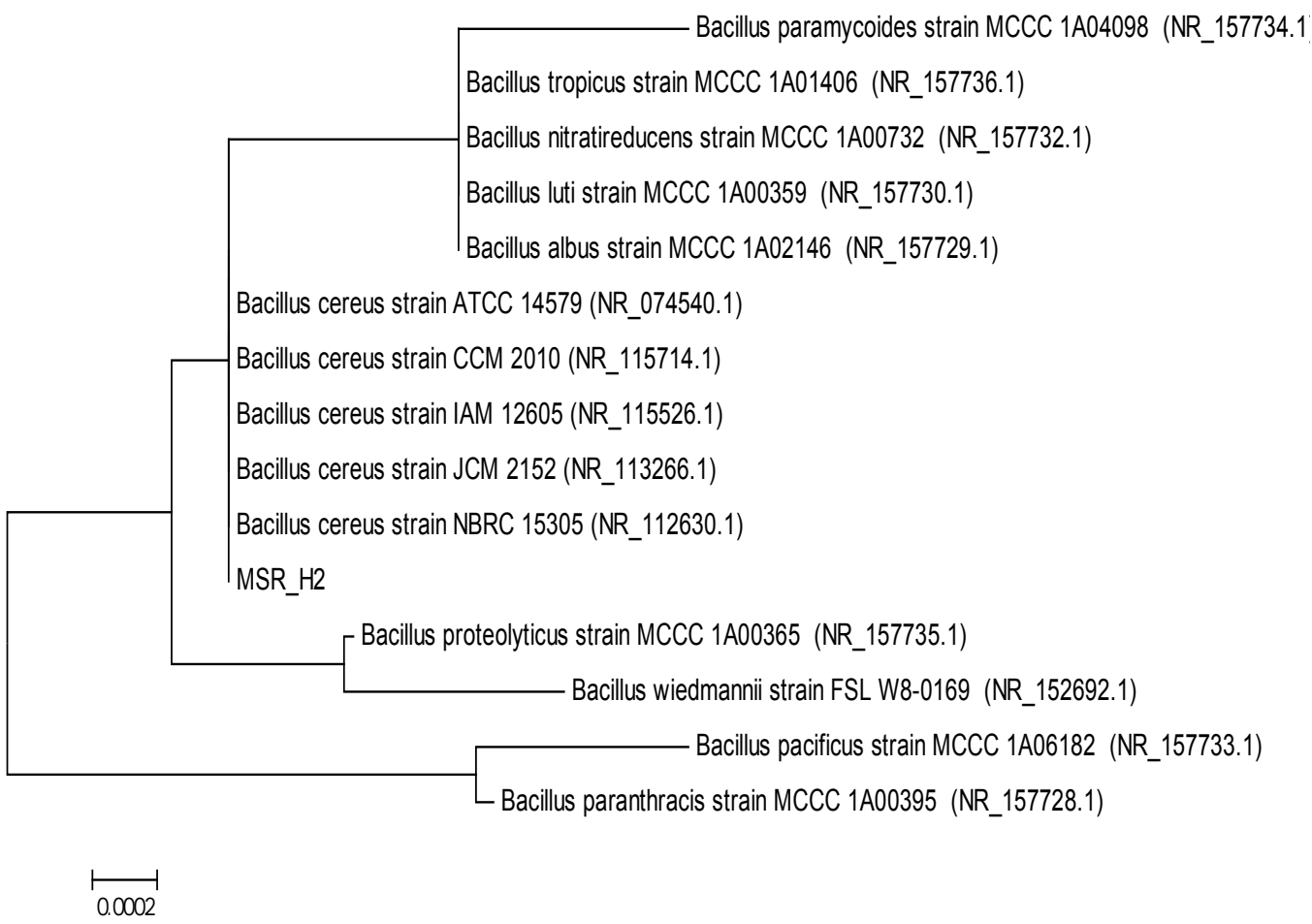

Fig. 1. Phylogenetic tree of rhizosphere bacteria based on 16S rRNA gene sequence comparison. Evolutionary relationships of the bacterial strains inferred using the Neighbor-Joining method and the evolutionary distances were computed using the Kimura 2-parameter method. GenBank accession numbers of strains are presented in parentheses. Bootstrap test (1,000 replicates). 
H1 was found to belong to phyla Firmicutes and were highly aligned with the genera Bacillus with close relation to Bacillus cereus (99\%) sequence similarity. We proposed the name of our isolate as Bacillus cereus strain MSR_H1 (Fig. 1).

\section{Field experiment}

Vegetative growth

Results of vegetative growth parameters (Leaf dry weight (LDW), shoot dry weight (SDW), root dry weight (RDW), total dry weight (TDW) and
(Shoot/Root ratio) as affected by inoculation with MSR-H1plus different rates of $\mathrm{K}$ silicates under drought stress are presented in (Table 3). There is a significant variation as a result of application of $\mathrm{K}$ silicate only or when combined with inoculation with bacteria in all growth parameters compared to control. Drought reduced all growth parameters while the highest growth rate was associated with $150 \mathrm{ppm}$ application plus bacteria, on the other hand, the small concentrations of $\mathrm{K}$ silicates (50

TABLE 3. Effect of bacterial inoculation and foliar application of Potassium silicate rates on Leaf dry weight (LDW), shoot dry weight (SDW), root dry weight RDW), total dry weight (TDW) and Shoot/Root ratio ( $\mathrm{S} / \mathrm{R}$ ) ratio under drought stress conditions on sorghum plants during season 2017.

\begin{tabular}{|c|c|c|c|c|c|c|c|c|c|c|}
\hline \multirow{2}{*}{ Treatments } & \multicolumn{2}{|c|}{ LDW (g) } & \multicolumn{2}{|c|}{ SDW (g) } & \multicolumn{2}{|c|}{ RDW (g) } & \multicolumn{2}{|c|}{ TDW (g) } & \multicolumn{2}{|c|}{$\begin{array}{l}\text { Shoot } / \text { Root } \\
\text { ratio }\end{array}$} \\
\hline & $45^{\text {th }} \mathrm{d}$ & $75^{\text {th }} \mathrm{d}$ & $45^{\text {th }} \mathrm{d}$ & $75^{\text {th }} d$ & $45^{\text {th }} \mathrm{d}$ & $75^{\text {th }} \mathrm{d}$ & $45^{\text {th }} d$ & $75^{\text {th }} d$ & $45^{\text {th }} d$ & $75^{\text {th }} \mathrm{d}$ \\
\hline $\mathbf{T 1}=$ Control & 16.97 & 18.61 & 36.14 & 38.71 & 29.28 & 34.11 & 66.17 & 72.81 & 1.23 & 1.13 \\
\hline $\mathbf{T} 2=$ Drought & 5.44 & 9.28 & 20.51 & 26.14 & 16.04 & 19.81 & 36.55 & 45.95 & 1.28 & 1.32 \\
\hline $\mathbf{T} 3=\mathrm{K}-\mathrm{Si} 50$ & 7.18 & 12.04 & 26.07 & 28.00 & 22.61 & 24.21 & 48.68 & 52.11 & 1.15 & 1.16 \\
\hline $\mathbf{T} 4=\mathrm{K}-\mathrm{Si} 150$ & 8.04 & 13.08 & 24.07 & 28.21 & 20.44 & 24.68 & 44.48 & 52.99 & 1.18 & 1.14 \\
\hline $\mathbf{T} 5=\mathrm{K}-\mathrm{Si} 200$ & 6.41 & 10.40 & 22.07 & 26.77 & 20.74 & 21.71 & 44.81 & 48.48 & 1.07 & 1.23 \\
\hline $\mathbf{T 6}=$ B. cereus & 9.10 & 14.64 & 29.28 & 31.58 & 23.06 & 27.14 & 52.34 & 57.32 & 1.27 & 1.16 \\
\hline $\begin{array}{l}\mathbf{T} 7=\text { B. cereus }+\mathrm{K}-\mathrm{Si} \\
50\end{array}$ & 9.91 & 14.31 & 29.21 & 31.54 & 23.11 & 27.31 & 52.32 & 72.26 & 1.26 & 1.15 \\
\hline $\begin{array}{l}\mathbf{T} 8=\text { B. cereus }+\mathrm{K}-\mathrm{Si} \\
150\end{array}$ & 11.17 & 16.28 & 35.84 & 37.00 & 27.01 & 29.81 & 62.85 & 66.82 & 1.34 & 1.24 \\
\hline $\begin{array}{l}\text { T9=B. cereus }+\mathrm{K}-\mathrm{Si} \\
200\end{array}$ & 9.24 & 14.84 & 31.04 & 37.04 & 26.71 & 26.57 & 57.72 & 61.81 & 1.14 & 1.39 \\
\hline L.S.D at 0.05 & 0.336 & 0.472 & 0.550 & 0.959 & 0.496 & 0.440 & 0.601 & 0.687 & ------ & ------ \\
\hline
\end{tabular}

ppm) only was less pronounced. The highest growth parameters $(11.17 \mathrm{gLDW}, 35.84 \mathrm{gSDW}$ and $27.01 \mathrm{gRDW}$ ) were obtained at T8 treatment (inoculation with bacteria and spraying by 150 ppm K silicates) after 45 days after sowing).

\section{Physiological characteristics}

There was a significant effect of MSR-H1 and Si application on Physiological characteristics including relative water content RWC, electrolyte leakage and Proline content of sorghum grown under drought stress (Table 4). In general, PGPRs inoculation plus $\mathrm{K}-\mathrm{Si}$ significantly increased RWC under drought treatment decreases. The lowest RWC was noted $61.6 \%$ at T3 (Si 50 ppm). Conversely, RWC improved by inoculation with bacteria plus applied K silicate 50, 150 and 200 Env. Biodiv. Soil Security Vol. 2 (2018) ppm recorded 77.1, 81.2 and 81.1 respectively. Electrolyte leakage (\%), reduction in electrolyte leakage was $22.47 \%$ in case of T3 (K-Si 50 ppm) compared with control. Conversely, inoculation with PGPRs plus Si (50, 150,200ppm) improved electrolyte leakage, recorded $76.2 \%, 82.2 \%$ and $80.2 \%$ respectively, compared to control under drought. Under water deficit conditions, sorghum plants received Si concentration showed lower Proline concentration in leaves (Table 4). Minimum proline content was $(6.7 \mathrm{mg} / \mathrm{g} \mathrm{d.w})$ found in $\mathrm{T} 1$ treatment (control under normal conditions) which increased by $58.65 \%$ in case of T2 (control under drought conditions), conversely, the proline content was reduced by applied Si concentrations 50, 150, 200 ppm 
TABLE 4. Effect of bacterial inoculation and foliar application of Potassium silicate rates on relative water content (R. W.C \%), Electrolyte leakage (\%) and Proline content on sorghum plant under drought stress conditions during season 2017.

\begin{tabular}{lccc}
\hline \multicolumn{1}{c}{ Treatments } & $\begin{array}{c}\text { R.W.C } \\
\text { (\%) }\end{array}$ & $\begin{array}{c}\text { Electrolyte } \\
\text { leakage } \mathbf{( \% )}\end{array}$ & $\begin{array}{c}\text { Proline } \\
\text { (mg /gd. } \mathbf{~ w ) ~}\end{array}$ \\
\hline T1=Control & 98.9 & 51.1 & 6.7 \\
T2=Drought & 72.0 & 91.2 & 10.63 \\
T3=K-Si 50 & 61.6 & 70.7 & 9.5 \\
T4=K-Si 150 & 64.5 & 71.8 & 8.8 \\
T5=K-Si 200 & 61.3 & 70.9 & 8.4 \\
T6=B. cereus & 76.5 & 73.6 & 8.6 \\
T7=B. cereus + K-Si 50 & 77.1 & 76.2 & 8.1 \\
T8=B. cereus + K-Si 150 & 81.2 & 82.2 & 7.2 \\
T9=B. cereus + K-Si 200 & 81.1 & 80.2 & 7.0 \\
L.S.D at 0.05 & 0.927 & 0.916 & 0.270 \\
\hline
\end{tabular}

recorded $10.63 \%, 17.21 \%, 20.97 \%$ respectively. With $\mathrm{PGPR}_{\mathrm{S}}$ inoculation plus concentration of $\mathrm{Si}$ application $(50,150$ and $200 \mathrm{ppm})$ the reduction in of proline content were $23.6 \%, 32.1 \%$ and $34.14 \%$ respectively.

Photosynthetic pigments

Water deficit caused a significant decrease in photosynthetic pigments, the reduction in Chl.a, Chl.b, Carotenoids and total chlorophyll were
$50 \%, 68 \%, 61 \%$ and $41 \%$ respectively after 45 DAS. Application of Si had significant effects on photosynthesis; it improved chlorophyll a, b and carotenoids as well as total chlorophyll in all treatments compared to control under drought (T2). Spraying with K-Si 50 (T3) and 150 (T4) ppm only led to increase in the Chla $(20 \%, 25 \%)$ over control (T2) after 45 days. Generally, applied to Si 200 ppm had a little effect on photosynthesis. Inoculation with PGPRs only (T6) or with K-Si

TABLE 5. Effect of bacterial inoculation and foliar application of Potassium silicate rates on chlorophyll a, chlorophyll b, carotenoids and total chlorophyll under drought stress conditions on sorghum plants during season 2017.

\begin{tabular}{|c|c|c|c|c|c|c|c|c|}
\hline \multirow[t]{2}{*}{ Treatments } & \multicolumn{2}{|c|}{$\begin{array}{c}\text { Chl.a } \\
\text { ( mg/g. fresh } \\
\text { weight ) }\end{array}$} & \multicolumn{2}{|c|}{$\begin{array}{l}\text { Chl.b } \\
\text { (mg /g. fresh } \\
\text { weight) }\end{array}$} & \multicolumn{2}{|c|}{$\begin{array}{l}\text { Carotenoids } \\
\text { (mg/g. fresh } \\
\text { weight) }\end{array}$} & \multicolumn{2}{|c|}{$\begin{array}{c}\text { Total } \\
\text { chlorophyll } \\
\text { ( mg/g. fresh weight) }\end{array}$} \\
\hline & $45^{\text {th }} d$ & $75^{\text {th }} d$ & $45^{\text {th }} d$ & $75^{\text {th }} d$ & $45^{\text {th }} d$ & $75^{\text {th }} d$ & $45^{\text {th }} d$ & $75^{\text {th }} d$ \\
\hline $\mathbf{T 1}=$ Control & 6.64 & 7.94 & 3.34 & 6.01 & 2.01 & 2.92 & 6.77 & 7.31 \\
\hline $\mathbf{T} 2=$ Drought & 3.28 & 3.86 & 1.04 & 2.78 & 0.77 & 0.90 & 3.95 & 4.21 \\
\hline $\mathbf{T} 3=\mathrm{K}-\mathrm{Si} 50$ & 3.96 & 4.07 & 2.58 & 3.02 & 0.59 & 1.00 & 4.01 & 5.55 \\
\hline $\mathbf{T 4}=\mathrm{K}-\mathrm{Si} 150$ & 4.11 & 4.11 & 2.64 & 3.21 & 1.00 & 1.20 & 4.87 & 5.85 \\
\hline T5=K-Si 200 & 4.01 & 4.11 & 2.00 & 3.07 & 0.89 & 1.00 & 4.15 & 5.82 \\
\hline $\mathbf{T} \mathbf{6}=B$. cereus & 4.68 & 5.65 & 2.24 & 4.71 & 1.04 & 1.00 & 5.88 & 6.57 \\
\hline $\mathbf{T} 7=$ B. cereus $+\mathrm{K}-\mathrm{Si} 50$ & 5.01 & 6.08 & 2.96 & 4.75 & 1.72 & 1.80 & 5.92 & 6.89 \\
\hline $\begin{array}{l}\mathbf{T} 8=\text { B. cereus }+\mathrm{K}-\mathrm{Si} \\
150\end{array}$ & 5.21 & 6.80 & 3.06 & 5.11 & 1.83 & 1.93 & 5.89 & 7.00 \\
\hline $\begin{array}{l}\mathbf{T} 9=B . \text { cereus }+\mathrm{K}-\mathrm{Si} \\
200\end{array}$ & 5.00 & 6.00 & 2.89 & 5.00 & 1.73 & 1.88 & 6.00 & 6.37 \\
\hline L.S.D at 0.05 & 0.390 & 0.391 & 0.197 & 0.197 & 0.059 & 0.059 & 0.223 & 0.223 \\
\hline
\end{tabular}


application $(50,150 \mathrm{ppm})$ mitigated the adverse drought effects, the highest increase was recorded with PGPRs plus 150 ppm recorded $76 \%$ increase in $\mathrm{Chl} \mathrm{a}, 83 \%$ in $\mathrm{Chl} \mathrm{b}, 114 \%$ in carotenoids and $66 \%$ in total chlorophyll after 75 DAS over control (T2) (Table 5).

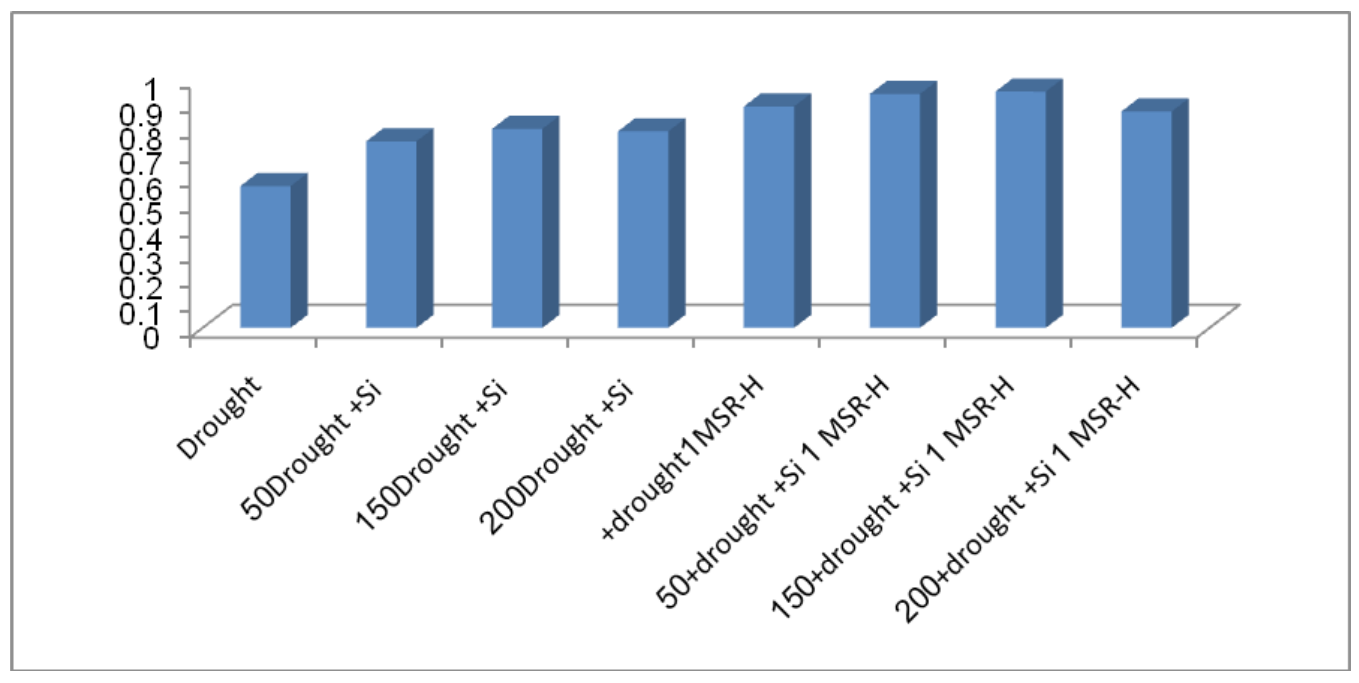

Fig. 2. Effect of bacterial inoculation and Si application on chlorophyll stability index (CSI) of sorghum plant under drought stress conditions.

Chlorophyll stability index

The chlorophyll stability index decreased under water deficit conditions (Fig. 2), conversely, it increased with application with $\mathrm{K}-\mathrm{Si}$ alone or in combination with bacterial inoculation. The highest chlorophyll stability index noted with inoculation by MSR-H1 (T6) followed by application of Si 150 ppm plus MSR-H1 (T8).

\section{Soil Biological activities}

\section{Microbial population}

Control under drought (T2) recorded the lowest total bacterial count, total fungi, actinomycetes and silicate bacteria $6.37 \times 10^{6}, 10.05 \times 10^{4,3.27 \times 10^{4}}$ and $15.47 \times 10^{4} \mathrm{CFU} \cdot \mathrm{g}^{-1}$ soil respectively after 45 days. The highest total bacteria count was noted with inoculation with PGPR plus 150 ppm K-Si (T8) application $39.77 \times 10^{6}$ after 75 days, while at the same treatment fungal population recorded

TABLE 6. Effect of bacterial inoculation and foliar application of Potassium silicate rates on total bacterial, fungal and Actinomycetes count (CFU) under drought stress conditions on sorghum plants during season 2017

\begin{tabular}{|c|c|c|c|c|c|c|c|c|}
\hline \multirow[t]{2}{*}{ Treatments } & \multicolumn{2}{|c|}{$\begin{array}{c}\text { Bacteria } \\
\left(\mathbf{x 1 0}^{6} \mathrm{CFU} \mathrm{g}^{-1}\right. \\
\text { soil })\end{array}$} & \multicolumn{2}{|c|}{$\begin{array}{c}\text { Fungi } \\
\left(\times 10^{4} \mathrm{CFU} \mathrm{g}^{-1}\right. \\
\text { soil })\end{array}$} & \multicolumn{2}{|c|}{$\begin{array}{c}\text { Actinomycetes } \\
\left(\times 10^{4} \mathrm{CFU} \mathrm{g}^{-1}\right. \\
\text { soil })\end{array}$} & \multicolumn{2}{|c|}{$\begin{array}{l}\text { Silicate bacteria } \\
\left(\times 10^{4} \mathrm{CFU} \mathrm{g}^{-1}\right. \\
\text { soil })\end{array}$} \\
\hline & $45^{\text {th }} d$ & $75^{\text {th }} d$ & $45^{\text {th }} d$ & $75^{\text {th }} d$ & $45^{\text {th }} d$ & $75^{\text {th }} d$ & $45^{\text {th }} d$ & $75^{\text {th }} d$ \\
\hline $\mathbf{T 1}=$ Control & 30.6 & 55.66 & 27.3 & 33.68 & 7.25 & 9.3 & 42.47 & 50.13 \\
\hline $\mathbf{T} 2=$ Drought & 6.37 & 10.25 & 10.05 & 12.07 & 3.27 & 4.88 & 15.47 & 19.16 \\
\hline $\mathbf{T 3}=\mathrm{K}-\mathrm{Si} 50$ & 14.89 & 20.54 & 13.11 & 13.11 & 1.60 & 2.56 & 22.67 & 27.14 \\
\hline $\mathbf{T 4}=\mathrm{K}-\mathrm{Si} 150$ & 17.56 & 25.77 & 13.15 & 13.58 & 1.8 & 2.68 & 24.45 & 26.34 \\
\hline T5=K-Si 200 & 17.25 & 23.36 & 12.83 & 13.28 & 1.66 & 2.3 & 23.85 & 31.93 \\
\hline $\mathbf{T 6}=B$. cereus & 23.48 & 33.40 & 11.22 & 11.25 & 3.47 & 4.04 & 33.07 & 38.04 \\
\hline $\mathbf{T} 7=$ B. cereus $+\mathrm{K}-\mathrm{Si} 50$ & 22.44 & 39.91 & 9.53 & 10.14 & 4.36 & 5.62 & 36.38 & 40.04 \\
\hline $\mathbf{T 8}=$ B. cereus $+\mathrm{K}-\mathrm{Si} 150$ & 28.92 & 39.77 & 8.06 & 10.88 & 5.42 & 5.51 & 34.79 & 42.05 \\
\hline $\mathbf{T} 9=$ B. cereus $+\mathrm{K}-\mathrm{Si} 200$ & 27.55 & 38.10 & 9.78 & 10.19 & 5.47 & 5.24 & 36.77 & 44.04 \\
\hline L.S.D at 0.05 & 1.114 & 3.104 & 0.447 & 0.291 & 0.668 & 0.696 & 4.097 & 1.266 \\
\hline
\end{tabular}

Env. Biodiv. Soil Security Vol. 2 (2018) 
the lowest value among other treatments 9.78 and $10.19 \times 10^{4}$ after 45 and 75 days respectively. Actinomycetes recorded the highest number in case of MSR-H1plus K silicates $50 \mathrm{ppm}$. The highest population of silicate bacteria was recorded at 75 days with inoculation PGPRs plus 200ppm K silicates $44.04 \times 10^{4} \mathrm{CFU} \mathrm{g}^{-1}$ soil (Table $6)$.

\section{Soil pH}

Changes in the $\mathrm{pH}$ of soil due to $\mathrm{K}$ silicates application are presented in Fig. 3. Data illustrated that there is no significantly increased in soil $\mathrm{pH}$ during the experiment trite after 45 and 75 DAS. However, $\mathrm{K}$ silicate slightly influences in soil $\mathrm{pH}$ and low it by up to 7.2 equivalents making the soil more natural. Microbial populations are affected

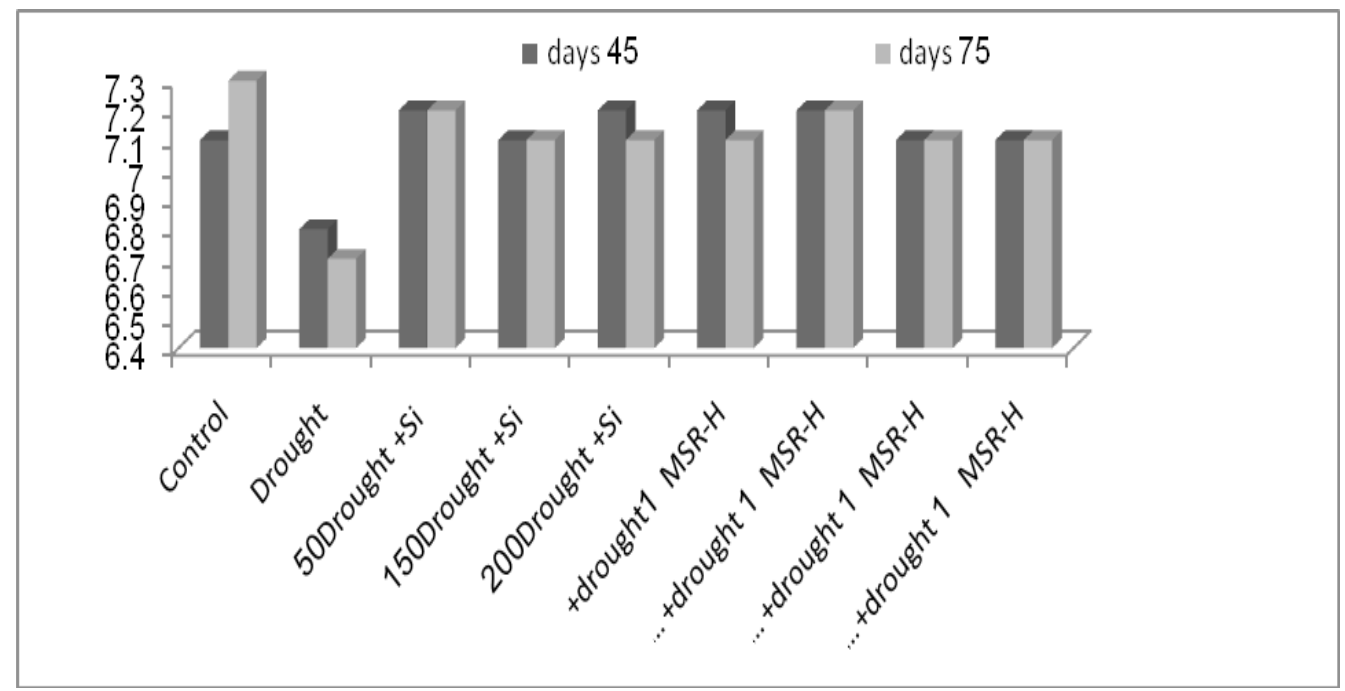

Fig. 3. Effect of bacterial inoculation and $\mathrm{Si}$ application on soil $\mathrm{pH}$ of sorghum plants under drought stress conditions.

with $\mathrm{pH}$ of soil (alkaline or acidic). Under drought conditions the $\mathrm{pH}$ of soil was decreased after 45 and 75 DAS recorded 6.8 and 6.7 respectively. In this study, the concentration of silicon application had a little effect in the soil $\mathrm{pH}$ during the state of growth sorghum plants whereas compared with under drought stress the $\mathrm{pH}$ of soil decreased.
Antioxidant activity

Under drought stress T2, Catalase (CAT) recorded the highest activity $24.3\left(\mu \mathrm{mol} \mathrm{H}_{2} \mathrm{O}_{2}\right.$ $\mathrm{mg}^{-1}$ protein $\mathrm{min}^{-1}$ ), Ascorbate Peroxidase (APX), $19.9\left(\mu \mathrm{mol}\right.$ ASA $\mathrm{mg}^{-1}$ protein $\mathrm{min}^{-1}$ ) and 15.7 $(\mu \mathrm{mol} / 100 \mathrm{~g} \mathrm{FW})$ for Super Oxide Dismutase (SOD). Conversely application of $\mathrm{K}$ silicates only 50,150 and $200 \mathrm{ppm}$ led to reduction in the

TABLE 7. Effect of bacterial inoculation and foliar application of Potassium silicate rates on ant oxidative enzymes under drought stress conditions on sorghum plants during season 2017.

\begin{tabular}{|c|c|c|c|}
\hline Treatments & $\begin{array}{c}\mathrm{CAT} \\
\mu \mathrm{mol} \mathrm{H}_{2} \mathrm{O}_{2} \mathrm{mg}^{-1} \\
\text { protein } \mathrm{min}^{-1}\end{array}$ & $\begin{array}{c}\text { APX } \\
\mu \text { mol ASA mg } \\
\text { protein } \text { min }^{-1}\end{array}$ & $\begin{array}{c}\text { SOD } \\
\mu / 100 \mathrm{~g} F W\end{array}$ \\
\hline $\mathbf{T 1}=$ Control & 8.8 & 6.8 & 8.8 \\
\hline $\mathbf{T} 2=$ Drought & 24.3 & 19.9 & 15.7 \\
\hline $\mathbf{T} 3=\mathrm{K}-\mathrm{Si} 50$ & 13.2 & 14.4 & 13.7 \\
\hline $\mathbf{T 4}=\mathrm{K}-\mathrm{Si} 150$ & 12.8 & 15.1 & 13.9 \\
\hline T5=K-Si 200 & 10.9 & 14.13 & 11.4 \\
\hline $\mathbf{T} \mathbf{6}=B$. cereus & 11.7 & 14.4 & 11.8 \\
\hline $\mathbf{T} 7=$ B. cereus $+\mathrm{K}-\mathrm{Si} 50$ & 14.3 & 12.2 & 11.9 \\
\hline $\mathbf{T} 8=$ B. cereus $+\mathrm{K}-\mathrm{Si} 150$ & 10.7 & 12.3 & 10.9 \\
\hline $\mathbf{T} \mathbf{9}=$ B. cereus $+\mathrm{K}-\mathrm{Si} 200$ & 10.0 & 11.7 & 7.0 \\
\hline L.S.D at 0.05 & 0.569 & 0.859 & 0.412 \\
\hline
\end{tabular}


activity of CAT enzyme $45.67 \%, 47.3 \%$ and $55.14 \%$ respectively compared with control under drought. Also, inoculation with $\mathrm{PGPR}_{\mathrm{S}}$ bacteria plus application of $\mathrm{K}$ silicates significantly reduced the activity of CAT $41.15 \%, 55.96 \%$ and $58.84 \%$ respectively, and APX14.4, 12.2 and 11.7 $\mu \mathrm{mol}$ and SOD 11.9, 10.9 and $7.0 \mu / 100 \mathrm{~g} \mathrm{FW}$

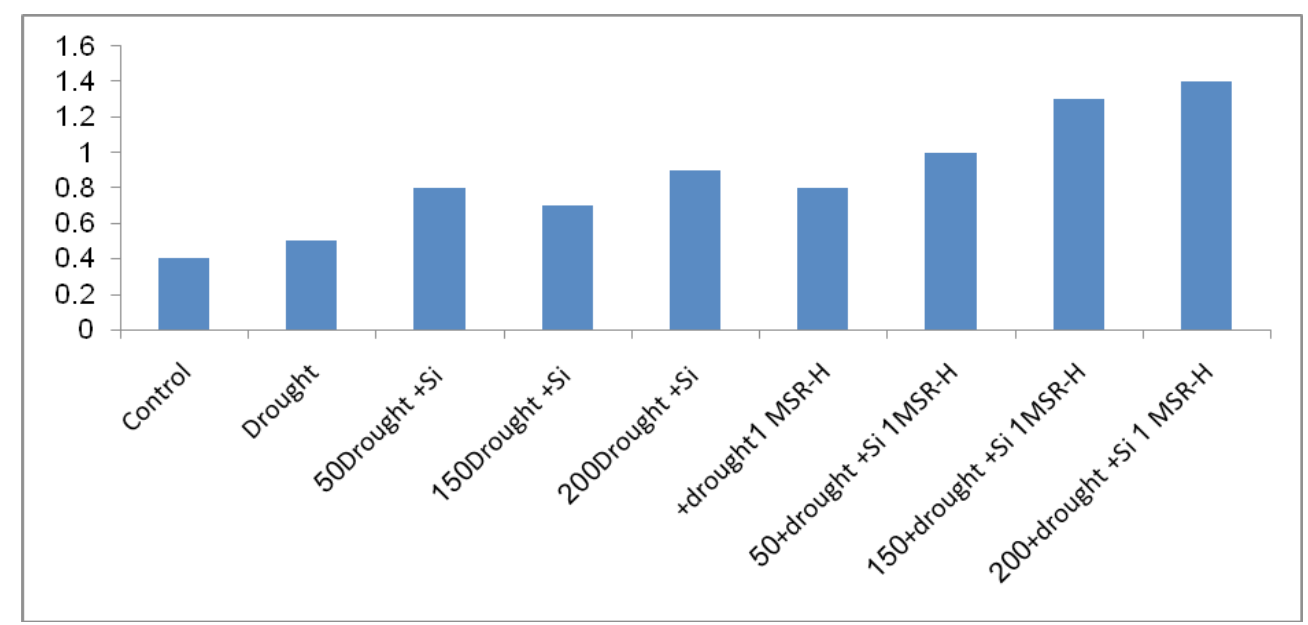

Fig. 4. Effect of bacterial inoculation and Si application on osmotic potential of sorghum plants under drought stress conditions.

compared to control (T2) (Table 7).

\section{Osmotic potential}

Data showed that application with K silicates recorded an increase in osmotic potential compared to control. Inoculation with $\mathrm{PGPR}_{\mathrm{S}}$ plus application $\mathrm{K}$ silicates recorded higher osmotic potential, inoculation with PGPRs plus $200 \mathrm{ppm}$ from $\mathrm{K}$ silicates under drought stress gave highest osmotic potential compared with control (Fig. 4).

\section{Yield components}

Data presented in Table 8 show that, generally, drought stress significantly reduced plant height, grain panicle, grain yield, 100 grains weight and biological yield. There were significant differences among various treatments. The plant height reduced about $20 \%$, in control under drought compared to control under normal irrigation. Spraying with K silicates 50, 150 and $200 \mathrm{ppm}$ improved plant height about 5\%,11\% and $5 \%$ respectively compared to control under drought while the increase percent in case of inoculation with PGPRs plus concentration from $\mathrm{K}$ silicate 50, 150 and 200 ppm were 10\%, 15\% and $11 \%$ respectively. Inoculation with PGPR plus $150 \mathrm{ppm}$ of $\mathrm{K}$ silicate under drought stress recorded the highest grain panicle and grain yield recorded $49.3 \mathrm{~g}^{-1}$ and 2.00 (ton/fed) respectively. The reduction caused in control under drought in case of 100 grains weight and biological yield was $48 \%$ and $58 \%$ respectively compared to control under normal irrigation. The maximum 100 grains weight 26.2 (g) was achieved by the treatment by
PGPRs plus $150 \mathrm{~K}$ silicate. It was a significant difference by drought stress on biological yield, the reduction in biological yield under drought was $58.42 \%$ while inoculation PGPRs plus 150 ppm $\mathrm{K}$ silicate recorded 99.9 (g plant ${ }^{-1}$ ) respectively.

Drought tolerance index (DTI), Tolerance (TOL) and Yield stability index (YSI)

The DTI was significantly affected by drought, Si and PGPR (Table 8). Bacterial inoculation plus $\mathrm{K}$ silicate helped sorghum plants to grow under water deficit stress. Data showed that the highest DTI (0.92) noted for inoculation with PGPR plus $150 \mathrm{ppm} \mathrm{K}$ silicate and the lowest DTI (0.84) noted for treatment with $\mathrm{K}$ silicate $50 \mathrm{ppm}$. The DTI in case of treatment with $\mathrm{K}$ silicate 50, 100 and 200 ppm recorded $0.84,0.88$ and 0.84 respectively, while inoculation with PGPRs bacteria only under drought stress recorded 0.90 DTI.

\section{Mineral Contents}

Under water deficit stress, result (Table 9) showed that foliar application of 50, 150 and 200 ppm K silicate increased all ionic concentrations. K silicates 150 ppm recorded highest N, P, K, Ca and $\mathrm{Mg}$ recorded 27.6, 2.7, 24.5,4.01 and 2.43 (mg $\mathrm{g}^{-1}$ ) respectively. While Ksili cate $50 \mathrm{ppm}$ reduced $\mathrm{Na}$ uptake and enhanced $\mathrm{Na} / \mathrm{K}$ selectivity ratio recorded 4.81 and 0.21 . ( $\left.\mathrm{mg} \mathrm{g}^{-1}\right)$ respectively. Application of $\mathrm{Si}$ and PGPR improved shoot $\mathrm{N}$ concentration by $42 \%, 46 \%$ and $40 \%$ respectively. The improvement in shoot $\mathrm{P}$ was $80 \%, 85 \%$ and $50 \%$ with Si $(50,150,200 \mathrm{ppm})$ application and PGPRs respectively. $\mathrm{Na}^{+}$concentration in control 
TABLE 8. Effect of bacterial inoculation and foliar application of Potassium silicate rates on yield component of sorghum plant under drought stress conditions on sorghum plants during season 2017.

\begin{tabular}{|c|c|c|c|c|c|c|c|c|}
\hline Treatments & $\begin{array}{c}\text { Plant } \\
\text { height } \\
(\mathrm{cm})\end{array}$ & $\begin{array}{c}\text { Grain } \\
\text { panicle } \\
{ }^{1}(\mathrm{~g})\end{array}$ & $\begin{array}{c}\text { Grain } \\
\text { yield } \\
\left.{\left.\text { (Ton } \text { fed }^{-1}\right)}^{-1}\right)\end{array}$ & $\begin{array}{c}100 \\
\text { grains } \\
\text { weight } \\
\text { (g) }\end{array}$ & $\begin{array}{l}\text { Biological } \\
\text { yield } \\
\text { (g) } \\
\text { Plant }^{-1}\end{array}$ & $\begin{array}{c}\text { Drought } \\
\text { tolerance } \\
\text { index }\end{array}$ & $\begin{array}{c}\text { Tolerance } \\
\text { (TOL) }\end{array}$ & $\begin{array}{c}\text { Yield } \\
\text { stability } \\
\text { index } \\
\text { (YSI) }\end{array}$ \\
\hline $\mathbf{T} 1=$ Control & 142.1 & 52.3 & 2.65 & 31.6 & 112.1 & -------- & ------------ & --------- \\
\hline $\mathbf{T} 2=$ Drought & 113.1 & 30.7 & 1.22 & 16.2 & 64.6 & 0.79 & 47.5 & 0.57 \\
\hline $\mathbf{T} 3=\mathrm{K}-\mathrm{Si} 50$ & 119.7 & 38.9 & 1.52 & 23.2 & 81.2 & 0.84 & 30.5 & 0.72 \\
\hline $\mathbf{T 4}=\mathrm{K}-\mathrm{Si} 150$ & 125.7 & 40.3 & 1.52 & 24.0 & 85.5 & 0.88 & 26.6 & 0.76 \\
\hline $\mathbf{T} 5=\mathrm{K}-\mathrm{Si} 200$ & 119.6 & 38.9 & 1.58 & 23.1 & 81.2 & 0.84 & 30.9 & 0.72 \\
\hline $\mathbf{T} \mathbf{6}=$ B. cereus & 128.3 & 44.8 & 1.80 & 25.0 & 98.1 & 0.90 & 14 & 0.88 \\
\hline $\mathbf{T} 7=$ B. cereus $+\mathrm{K}-\mathrm{Si} 50$ & 125.0 & 46.3 & 1.96 & 25.4 & 96.4 & 0.88 & 15.7 & 0.86 \\
\hline $\mathbf{T} 8=B$. cereus $+\mathrm{K}-\mathrm{Si} 150$ & 130.9 & 49.3 & 2.00 & 26.2 & 99.9 & 0.92 & 12.2 & 0.89 \\
\hline $\mathbf{T} \mathbf{9}=$ B. cereus $+\mathrm{K}-\mathrm{Si} 200$ & 125.6 & 46.9 & 1.94 & 24.2 & 94.3 & 0.88 & 17.7 & 0.84 \\
\hline L.S.D at 0.05 & 1.225 & 1.012 & 0.171 & 0.477 & 3.259 & ----------- & ----------- & ------. \\
\hline
\end{tabular}

TABLE 9. Effect of bacterial inoculation and foliar application of Potassium silicate rates on macronutrient (N, $\mathrm{P}, \mathrm{K}, \mathrm{Na}, \mathrm{Ca}, \mathrm{Mg}$ and $\mathrm{Na} / \mathrm{K}$ ratio) in shoots of sorghum plants under drought stress conditions during season 2017.

\begin{tabular}{|c|c|c|c|c|c|c|c|}
\hline \multirow[b]{2}{*}{ Treatments } & \multicolumn{7}{|c|}{ Nutrients (mg g ${ }^{-1}$ plant) } \\
\hline & $\mathbf{N}^{-3}$ & $\mathbf{P}^{-3}$ & $\mathbf{K}^{+}$ & $\mathbf{N a}^{+}$ & $\mathbf{C a}^{+2}$ & $\mathbf{M g}^{+2}$ & $\begin{array}{c}\mathrm{Na}^{+} / \mathrm{K}^{+} \\
\text {ratios }\end{array}$ \\
\hline T1 $=$ Control & 30.6 & 3.8 & 36.93 & 2.31 & 7.51 & 4.58 & 0.06 \\
\hline $\mathbf{T} 2=$ Drought & 18.8 & 2.0 & 19.8 & 5.24 & 3.68 & 2.31 & 0.26 \\
\hline $\mathbf{T} 3=\mathrm{K}-\mathrm{Si} 50$ & 25.8 & 2.7 & 23.4 & 4.81 & 3.97 & 2.34 & 0.21 \\
\hline $\mathbf{T} 4=\mathrm{K}-\mathrm{Si} 150$ & 26.6 & 2.7 & 24.5 & 4.11 & 4.01 & 2.43 & 0.17 \\
\hline $\mathbf{T} \mathbf{5}=\mathrm{K}-\mathrm{Si} 200$ & 24.4 & 2.6 & 22.9 & 3.98 & 3.90 & 2.27 & 0.17 \\
\hline $\mathbf{T 6}=B$. cereus & 25.7 & 3.7 & 25.2 & 3.92 & 4.96 & 2.76 & 0.16 \\
\hline $\mathbf{T} 7=$ B. cereus $+\mathrm{K}-\mathrm{Si} 50$ & 26.7 & 3.6 & 31.61 & 3.68 & 5.01 & 3.01 & 1.01 \\
\hline $\mathbf{T} 8=B$. cereus $+\mathrm{K}-\mathrm{Si} 150$ & 27.6 & 3.7 & 52.4 & 3.10 & 5.88 & 3.57 & 0.06 \\
\hline $\mathbf{T} 9=$ B. cereus $+\mathrm{K}-\mathrm{Si} 200$ & 26.4 & 3.0 & 31.13 & 3.03 & 5.87 & 3.48 & 0.27 \\
\hline L.S.D at 0.05 & 0.651 & 0.093 & 9.950 & 0.083 & 0.282 & 0.187 & --------- \\
\hline
\end{tabular}

treatment was $2.31 \mathrm{mg} \mathrm{g}^{-1}$ which was increased to $5.24 \mathrm{mg} \mathrm{g}^{-1}$ compared to control. Application of $\mathrm{K}$ silicate plus PGPRs led to decreased shoot $\mathrm{Na}$ in all treatments. Application K silicate 50,150 and $200 \mathrm{ppm}$ recorded 4.81, 4.11 and $3.98\left(\mathrm{mg} \mathrm{g}^{-1}\right)$ respectively. The highest reduction in Na recorded with PGPRs plus 200ppm followed to PGPRs plus $\mathrm{K}$ silicate $150 \mathrm{ppm}$ recorded $3.10\left(\mathrm{mg} \mathrm{g}^{-1}\right)$ compared to drought stressed plants without any amendment.

\section{Discussion}

In this study, ten bacterial isolates were obtained from the rhizosphere of sorghum plants grown in Giza Govern., Egypt. The isolates are characterized to morphologically \& biochemically tested according to the Burges manual. These bacteria can produce phytohormones to stimulate plant growth under drought stress. IAA may play an important role in the promoting ability Radwan et al., (2002) and Torres et al. (2000) they found that PGPRs are able to produce IAA, gibberellins and cytokines in vitro and these phytohormones can help plants to grow and increase the germination rate.

Bacillus cereus MSR-H1 are able to phosphates production enzymes and these results are harmony with Cheng et al. (2017) and Agnieszka et al. (2018) they found that Bacillus spp is responsible role for releasing available forms of phosphorus (such as tricalcium phosphate, di calcium phosphate, and rock phosphate) to host plants in 
the soil through the production of organic acids and increase in activity of acid phosphatases responsible for the mineralization of organic phosphorous. PGPRs can produce exopolysac charides (E.P.S) which helps in the development of biofilm, protection from extremities and cement soil aggregates (Vanderlinde et al., 2010). Bacillus cereus MSR-H1 can able to siderophores production and the cyanide in vitro, Lalloo et al. (2010) mentioned the siderophore production from Bacillus cereus and they found that it can produce siderophore. José et al. (2017) showed that PGPRs inoculation led to increase in the tolerance of maize to drought stress and increased the growth parameters.

Isolate $\mathrm{H} 1$ can grow at media containing PEG $(10,20,30 \%)$, similar results recorded by Amrani et al. (2010); Fitouri et al. (2012) they reported that some species can grow in media counting PEG up to $25 \%$ in YMB media. Similarly, 45 strains of Rhizobium can grow in 60\% PEG. Drought stress caused a significant $(\mathrm{P} \leq 0.05)$ reduction in LDW, SDW and RDW. Showemimo and Olarewaju (2007) cleared that drought is biotic stress factors it, decreased the rate of growth, development and yields.

Vegetative growth parameters of sorghum plant were significantly improved by using foliar application of potassium silicate compared to the untreated ones. The foliar application of potassium silicate at $150 \mathrm{ppm}$ caused significant increase in LDW, SDW, RDW; these results are in complete accordance with (Taiichiro et al., 2005) which found that, the application of silicon led to increase in shoot heights and dry matter production.

Resulted indicated that inoculation with PGPRs plus application of K-Si under drought stress improved plant growth, these results are harmony with Taiz and Zeiger (2006), they found that drought-induced reduction in plant growth due to the mitigation in turgor pressure under drought conditions but inoculation of PGPRs plus Si with stress alleviated the detrimental effects of drought and increased plant growth and yield. PGPRs not only could help the germination of plant seed and consequent root elongation (Muralikannan and Anthomiraj 1998). RWC and electrolyte leakage are the indicatives of metabolic activeties within plants, these used for to different abiotic stress like drought. Under drought stress the RWC and electrolyte leakage of sorghum plants, Showemimo and Olarewaju (2007) reported that, drought stress increased electrolyte leakage and caused membrane instability in plants. Application of Si and inoculation of PGPRs alleviated drought stress effects and reduced electrolyte leakage.

Si supplementation could improve water storage within plant tissues in tomato by reducing transpiration and can reduce the bad effect of drought by accumulation of proline and soluble protein content (Romero-Aranda et al. 2006). (Sapre and Vakharia, 2016). Mauad et al. (2016) found that, proline content was reduced under water deficiency conditions, which could be an indicator of stress tolerance. Si and PGPRs could improve chlorophyll parameters and provide useful information on photosynthetic metabolism in stressed plants (Kastori et al., 2000) Maghsoudi et al. (2015). Oliveira et al. (2016) found that foliar application of silicon improved chlorophyll pigment ( $\mathrm{Chl}$ a, b and carotenoid's) concentration of wheat under water deficit conditions. High chlorophyll stability indices are a sign that plants withstand stress through better availability of chlorophyll(Madhan Mohan et al., 2000). K-Silicate application may cause significant decrease in soil fungi (Brecht et al., 2001).

Some bacterial species can solubilize silicates, phosphates by production of organic acids such as 2 keto-gluconic acids, alkalis and polysaccharides (Joseph et al., 2015). pH is helping microorganisms; to growth and improved the value of soil nutrient. Lauber et al. (2009) reported that the (alkaline or acidic) $\mathrm{pH}$ will affect microbial population, which in turn affects soil nutrient value. $\mathrm{PH}$ is a biomarker effect for growth, bacteria, fungi and soil nutritional value Rousk et al (2009).

Si application induced high drought tolerance by organizing antioxidant activities of CAT, SOD, and GR (Gong et al. 2005; Kohler et al. 2008). PGPRs can able to alleviate the oxidative damage produced under water shortage. Osmotic adjustment is very important mechanism of acclimation to drought (Arndt et al. 2000). High osmotic adjustment helps sorghum cope with drought (Machado and Paulsen 2001).

Sorghum under drought stress led to significant decrease in plant growth, grain and biological yields of sorghum plants (Ibrahim et al. 2013). The 100-seed weight and biological yields were decreased under water defiant conditions as a result to the reduction in the number of filled grains (Kousar et al. 2012); (Venuprasad et al. 
2007). The relationship between grain yield and water is complex because the sorghum is more sensitive to water and depends on water at certain growth stages (Garrity et al. 1982).

$\mathrm{Si}$ may be involved in metabolic or physiological and/or structural activity in higher plants exposed to abiotic and biotic stresses (Liang et al. 2003). Spraying silicon on plant leaves led to significant increase in grain yield comparing to control (without Si application) as a result of photosynthetic area increase which led to increasing in dry matter and number of spikes (Soratto et al. 2012; Pilon et al. 2013; ElHedek 2013). Inoculation with PGPRs improve drought tolerance index of the seedlings due to the production of osmolyte and antioxidants in the rhizosphere (Fitouri et al.,2012). Samarah et al. (2004) found that water deficit could affect nutrient uptake by decreasing nutrient transport from soil to root surface as well as by reducing root growth and extension. N, P and $\mathrm{K}$ uptake in sorghum were enhanced significantly by PGPRs inoculation and Silicon treatments. Silicon has played an important role in balancing the uptake, transport, of minerals in plants under water deficit (Nayer and Reza 2008). On the contrarily Soratto et al. (2012) found that the minerals concentration in plants did not affect by application of $\mathrm{Si}$ and the $\mathrm{K}$ concentration in leaves. The increased uptake of $\mathrm{Ca}$ and $\mathrm{K}$ may be attributed to a decrease in plasma membrane permeability and increase in plasma membrane $\mathrm{H}+$-ATP activity as a result of silicon addition (Kaya et al. 2006) and also PGPRs plus $\mathrm{Si}$ interacted with $\mathrm{Na}^{+}$, reduced its uptake while increased the concentration of $\mathrm{K}^{+}, \mathrm{Ca}^{2+}$ and $\mathrm{Mg}^{2+}$ in plant tissues.

\section{Conclusion}

Under water stress conditions, application of foliar $\mathrm{K}$ silicate individually or plus bacterial inoculation in sorghum plants can reduce drought stress and improve sorghum growth and yield in addition to their effects on physiological characteristics, photosynthetic pigments, chlorophyll stability index as well as improved soil biological activities, antioxidant activity which could be indicative of stress tolerance. Under water stress conditions PGPR inoculation plus $\mathrm{K}$ silicate succeed to alleviate drought stresses in sorghum plants.

\section{References}

Abdel-Motagally (2010) Evaluation of water use efficiency under different water Regime in grain sorghum (Sorghum bicolor L. Moench). World J. Agric. Sci., 6 (5): 499-505.

Aebi, H.E. (1983) Catalase. In "Method of Enzymatic Analysis", VCH, Weinheim, Germany-Deerfield, FL.: 3, 273-286.

Agarie, S.; H. Uchida.; W. Agata.; F. Kubota and P.B. Kaufman (1998) Effects of silicon on transpiration and leaf conductance in rice plants (Oryza sativa L.). Plant Prod Sci 1: 89-95.

Agnieszka Saeid.; P. Eweline and Justyna, D.L. (2018) Phosphorus Solubilization by Bacillus Species. Molecules, $23 \quad$ (11): 2897; doi:10.3390/ molecules 23112897

Ahmad, M. (2011) Microbial ACC-deaminase may improve the efficiency of Rhizobium inoculation in mung bean under salt affected conditions. $P h$. D. Thesis, University of Agriculture, Faisalabad, Pakistan.

Altschul, S. F., T. L.; Madden.; Schäffer.; J. Zhang.; Z. Zhang, Z., W. Miller., et al. (1997) Gapped BLAST and PSI-BLAST: A new generation of protein database search programs. Nucleic Acids Res. 25: 3389-3402. doi: 10.1093/nar/25.17.3389

Amrani, S.; N.E. Noureddine.; T. Bhatnagar.; M. Argandona; J.J. Nieto and C. Vargas.(2010) Phenotypic and genotypic characterization of rhizobia associated with Acacia saligna (Labill.) Wendl.in nurseries from Algeria. System Appl. Microbiol., 33: 44-51.

Arndt, S.K.; W. Wanek.; S.C. Clifford and M. Popp. (2000) Contrasting adaptations to drought stress in field-grown Ziziphusmauritiana and Prunus persica trees: Water relations, osmotic adjustment and carbon isotope composition. Aust. J. Plant Physiol. 27: 985-996.

Ashraf, M .and M. R.Foolad .(2007) Foolad Roles of glycine betaine and proline in improving plant abiotic stress resistance. Environmental and Experimental Botany, 59 (2): 206-216.

Awad, M.A; A.A. Soaud and S.M. El-Konaissi. (2006) Effect of exogenous application of anti-stress substances and elemental sulfur on growth and stress tolerance of tissue culture derived plantlets of date palm (Phoenix dactylifera L.) c.v. 'Khalas' during acclimatization. J. Appl. Hort. 8: 129-134.

Bakker, A. W. and B. Schippers. (1987) Microbial cyanide production in the rhizosphere in relation to potato yield reduction and Pseudomonas spp. Mediated plant growth stimulation. Soil Biol. Biochem., 19: 451-457.

Bates, I S.; R. P. Waldrem and I. D. Tear (1973) Rapid determination of free proline for water stress 
studies. Plant Soil., 39, 205-207.

Bertrand, H .; R. Nalin.; R. Bally and J.C.C Marel (2001) Isolation and identification of the most efficient plant growth promoting bacteria associated with canola. Biol. Fert. Soil 33: 152-156.

Black, C.A.; O.D. Ewans.; L.E.Ensminger.; J.L White.; F.E. Clark. and R.C Dinaver. (1982) Methods of soil Analysis part 2 Chemical and Microbiological Properties 2nd, Soil Sci. Soc. of Am. Inch. Publ., Madison, Wisconsin, U.S.A, pp.1572.

Brecht, M.L.; L.E. Datnoff.; T. Kucharek and R .Nagata (2001) Effect of silicon and hlorothalonil on suppression of gray leaf spot in St. Augustine grass. Phytopathology, 91: S11

Capell, B and K. Doerffling (1993) Genotypic specific differences in chilling tolerance of maize to chilling induced changes in water status and abscisic acid accumulation. Physiol Plant. 88: 683-694. doi:10.1111/j.1399-3054.1993.tb01383.x.

Cheng, J.; W. Zhuang; N.N. Li; C.L.Tang; H.J. Ying (2017) Efficient biosynthesis of d-ribose using a novel co-feeding strategy in Bacillus subtilis without acid formation. Lett. Appl. Microbiol. 64: 73-78.

Difco Manual, (1985) Dehydrated culture media and reagents for microbiology. Laboratories incorporated Detroit. Michigan, 48232 USA. p: 1027 and 621.

Donahue, J.L.; C.M. Okpodu.; C.L. Cramer.; E.A. Grabau and R.G. Alscher (1997) Responses of antioxidants to paraquat in pea leaves. Plant Physiol., 1131(1): 249-57.

Edgar, R. C. (2004) MUSCLE: multiple sequence alignment with high accuracy and high throughput. Nucleic Acids Res. 32: 1792-1797. doi: 10.1093/ nar/gkh340

El-Hedek, K.S. (2013) Effect of foliar applications of salicylic acid and potassium silicate on tolerance of wheat plants to soil salinity. J. Soil Sci. and Agric. Eng., Mansoura Univ., 4(3): 335-357.

FAO (2012) Food and Agriculture Organization of the United Nations.http://faostat.fao.org/site/339/ default.aspx.

Farshadfar, E and J. Sutka (2002) Multivariate analysis of drought tolerance in wheat substitution lines. Cereal Res Commun 31: 33-39.

Fitouri, S.D.; D. Trabelsi.; S. Saïdi.; K. Zribi.; F.B. Jeddi and R. Mhamdi, (2012) Diversity of rhizobia nodulatingsulla (Hedysarumcoronarium L.) and selection of inoculants strains for semi-arid Tunisia. Ann. Microbiol., 62: 77-84.

Garrity, D. P.; G. W. Darrel.; Y. S Charles and R. Env. Biodiv. Soil Security Vol. 2 (2018)
G James (1982) Moisture deficits and grain sorghum performance: Evapotranspiration-yield relationships. Agron. J. 74, 815-820.

Gomez, K.A. and A.A. Gomez (1984) Statistical Procedures for Agricultural Research, 2nd Ed. John Wiley and Sons Ltd., New York, pp: 680.

Gong, H.; X. Zhu.; K. Chen.; S. Wang and C. Zhang. (2005) Silicon alleviates oxidative damage of wheat plants in pots under drought. Plant Sci. 169: 313-321. doi: 10.1016/j.plantsci..02.023

Gong, H.J.; K.M. Chen; G.C Chen; S.M Wang and C.L Zhang (2003) Effects of silicon on growth of wheat under drought. J. Plant Nutr 26: 1055-1063.

Gunes, A. et al. (2007a) Silicon- mediated changes on some physiological and enzymatic parameters symptomatic of oxidative stress in barley grown in sodic-B toxic soil. Journal of Plant Physiology, 164(6): 807-811.

Gunes, A.; D.J. Pilbeam; A. Inal and S. Coban. (2008) Influence of silicon on sunflower cultivars under drought stress, I: growth, antioxidant mechanisms, and lipid peroxidation. Communication in Soil Science and Plant Analysis 39: 1885-1903.

Holt, J.G.; N.R. Krieg; P.H.A. Sneath; J.T. Staley and S.T Williams (1994) In Bergy's Manual of Determinative Bacteriology, ninth ed., Williams and Wilkins Pub, MD, USA.

Ibrahim, A.H.; O.A. El-Shahaby; S.A. Abo-Hamed and M.E. Younis (2013) Parental drought and defoliation effect on yield, grains. Biochemical aspects and drought performance of sorghum progeny. J. Stress Physiol Biochem. 9: 258-272.

Joseph, M.H.; T.S. Dhargave; C.P. Deshpande and A.K. Srivastava (2015) Microbial Solubilisation of Phosphate: Pseudomonas versus Trichoderma. Annals of Plant and Soil Research, 17: 227-232.

José A. C.; I.D. Diego; E. F. Julián; B.B. Karina and E.B. Lautaro (2017) Inoculation with Azospirillum sp. and Herbaspirillum sp. Bacteria Increases the Tolerance of Maize to Drought Stress. Microorganisms, 5 (41): doi:10.3390/ microorganisms 5030041

Kastori, R.; M. Plesnicar; I. Arsenijevic-Maksimovic; N. Petrovic; D. Pankovic and Z. Sakac (2000) Photosynthesis, chlorophyll fluorescence and water relations in young sugar beet plants as affected by sulfur supply. J. Plant Nutr 23: 1037-1049.

Kaya, C., L. Tuna and D. Higgs (2006) Effect of silicon on plant growth and mineral nutrition of maize grown under water-stress conditions. J . Plant Nutr 29: $1469-1480$.

Kaya, C. and D. Higgs (2003) Supplementary potassium 
nitrate improves salt tolerance in bell pepper plants. Journal of Plant Nutrition 26: 1367-1382.

Kimura, M. (1980) A simple method for estimating evolutionary rates of base substitutions through comparative studies of nucleotide sequences. $J$. Mol. Evol. 16: 111-120. doi: 10.1007/BF01731581

Kloepper, J.W.; R. Rodriguez-Ubana; G.W Zehnder.; J.F. Murphy and E. Sikora (1999) Fernández, C. Plant root-bacterial interactions in biological control of soilborne diseases and potencialextensión to systemic and foliar diseases. Australas. Plant Pathol., 28: 21-26.

Kohler, J.; J.A Herna'indez.; F. Caravaca.; A. Roldain (2008) Plant-growth promoting rhizobacteria and arbuscular mycorrhizal fungi modify alleviation biochemical mechanisms in water stressed plants. Funct. Plant Biol. 35, 141-151. 28(8): 1423-1431.

Kousar, A.; S.A. Mallick; G. Moni; G. Sachin and A.K Mondal (2012) Drought stress responses of wheat genotypes with respect to nutritional quality. Indian J. Agri. Biochem. 25: 94-99.

Kumar, S., Stecher, G., and Tamura, K. (2016) MEGA7: molecular evolutionary genetics analysis version 7.0 for bigger datasets. Mol. Biol. Evol. 33: 1870 1874. doi: $10.1093 / \mathrm{molbev} / \mathrm{msw} 054$.

Lalloo, R., G. Moonsamy, S. Ramchuran, J. Gorgens and N. Gardiner (2010) Competitive exclusion as a mode of action of a novel Bacillus cereus aquaculture biological agent. Letters in Applied Microbiology, 50: 563-570.

Lauber, C.L., M. Hamady, R. Knight and N, Fierer (2009) Pyrosequencing-based assessment of soil $\mathrm{pH}$ as a predictor of soil bacterial community structure at the continental scale, Appl. Environ. Microbiol, 75: 5111-5120.

Liang Y.C.; Q. Chen; Q. Liu.; W.H. Zhang and R.X. Ding (2003) Exogenous silicon (Si) increases antioxidant enzyme activity and reduces lipid peroxidation in roots of salt-stressed barley (Hordeum vulgare L.). J. Plant Physiol 160: 1157-1164.

MA, J. F. et al.(2006) Silicon transporter in rice. Nature, 440 (7084): 688-691.

Machado, S. and G. M Paulsen (2001) Combined effect of drought and high temperature on water relations of wheat and sorghum. Plant Soil, 233: 179-187.

Madhan Mohan, M., S. Lakshmi Narayanan and S.M. Ibrahim (2000) Chlorophyll Stability Index (CSI): Its impact on salt tolerance in rice. Int. Rice Res. Notes, 25: 38-39.

Maghsoudi, K.; Y. Emam and M. Ashraf (2015) Influence of foliar application of silicon on chlorophyll fluorescence, photosynthetic pigments, and growth in water-stressed wheat cultivars differing in drought tolerance. Turkish Journal of Botany, 39: 625-634.

Margesin, R.; F. Schinner, (Eds.).(2005) 'Manual for Soil Analysis - Monitoring and Assessing Soil Bioremediation' (Springer-Verlag, Berlin Heidelberg, Germany, 2005) pp: 68-71.

Marsalis, M. A., S. V. Angadi, E. F. Contreas-govea (2010) Dry matter yield and nutritive value of corn, forage sorghum, and BMR forage sorghum at different plant population and nitrgen rates. Field Crops Res, 116 (1): 52-57.

Martin, G. W. (1951) The numbers of fungi. Proceedings of the Iowa. Academy of Science $\quad \mathbf{5 8}$ : 175 - 178.

Marulanda A.; R. Azco' n; J.M. Ru1'z-Lozano and R. Aroca (2008) Differential effects of a Bacillus megaterium strain on Lactuca sativa plant growth depending on the origin of the arbuscular mycorrhizal fungus coinoculated: physiologic and biochemical traits. J. Plant Growth Regul. 27: 1018.

Mauad, M., C. Crusciol., A. Nascente., H. Filho and G. Lima (2016) Effects of silicon and drought stress on biochemical characteristics of leaves of upland rice cultivars. Revista Ciência Agronômica, 47 (3): 532-539.

Mehta, S. and C.S Nautiyal (2001) An efficient method for qualitative screening of phosphate solubilizing bacteria. Curr. Microbial. 43: 51-58.doi: 10.1007/ s002840010259.

Mekdad, A.A.A and M.M. Rady (2016) Productivity Response to Plant Density in Five Sorghum Bicolor Varieties in Dry Environments. Annals of Agricultural \& Crop Sciences, 1 (2).

Muralikannan, N. and S. Anthomiraj (1998)Occurrence of Silicate Solublising Bacteria in Rice Ecosystem. The Madras Agricultural Journal, 85: 47-50.

Nakano, Y. and K. Asada (1981) Hydrogen peroxide is scavenged by acerbate-specific peroxidase in spinach chloroplasts. Plant Cell Physiol., 22, 867880 .

Nayer, M. and H Reza (2008) Drought-induced accumulation of soluble sugars and proline in two maize varieties. World App. Sci. J. 3: 448 -453.

Nornai, R. (1982) Formula for determination of chlorophyll pigments extracted with N.N. dimethylformamide. Plant Physiol. 69: 1371-1381.

Oliveira, J.R., M. Koetz., E.M. Bonfim-Silva and T.J. Silva (2016) Production and accumulation of silicon $(\mathrm{Si})$ in rice plants under silicate fertilization and soil water tensions. Australian Journal of Crop Science, 10 (2): 244-250. 
Pilon, C.; R.P. Soratto and L.A. Moreno (2013)Effects of soil and foliar application of soluble silicon on mineral nutrition, gas exchange, and growth of potato plants. Crop Science, 53: 1605-1614.

Potts, M. (1994) Desiccation tolerance of prokaryotes. Microbiol Rev. 58: 755 -805.

Radwan, T. E., K. Zeinat and Veronica R. Massena (2002) Factors affecting indole-3-acetic acid production by diazotrophic bacteria: Forms of nitrogen, aeration and soil conditions. Symbiosis. 32: $100-150$.

Rolf, A.O. and L.R. Bakken. (1987) Vibility of soil bacteria: optimization of plate counting technique and comparison between total counts and plate counts within different size groups. Micro. Ecol.,13: 59-74.

Romero-Aranda, M.R., O. Jurado and J. Cuartero. (2006) Silicon alleviates the deleterious salt effect on tomato plant growth by improving plant water status. Journal of Plant Physiology 163: 847-855.

Rousk, J., P.C. Brookes and E. Baath (2009) Contrasting soil $\mathrm{pH}$ effects on fungal and bacterial growth suggest functional redundancy in carbon mineralization, Appl. Environ. Microbiol., 75: 1589-1596.

Sairam, R.K., P.S. Deshmukh, D.S Shukla (1997) Tolerance of drought and temperature stress in relation to increased antioxidant enzyme activity in wheat. J. Agron Crop Sci 178: 171-178.

Saitou, N. and Nei, M. (1987) The neighbor-joining method: A new method for reconstructing phylogenetic trees. Molecular Biology and Evolution, 4: 406-425.

Samarah, N., R. Mullen and S. Cianzio (2004) Size distribution and mineral nutrients of soybean seeds in response to drought stress. J. Plant Nutr. 27: 815835.

Sapre, S.S. and D.N. Vakharia (2016) Role of silicon under water deficit stress in wheat:(Biochemical perspective): A review. Agricultural Reviews., 37(2): 109-116.

Sarwar, M., M. Arshad, D.A. Martens and W.T. Jr Frankenberger (1992) Tryptophan dependentbiosynthesis of auxins in soil. Plant Soil 147: 207-215.doi:10.1007/BF00029072.
Schwyn, B. and J.B. Neilands (1987) Universal chemical assay for the detection and determination of siderophores. Anal.Biochem., 160: 47- 56.

Showemimo, F. and J. Olarewaju (2007) Drought tolerance indices in sweet pepper (Capsicum annuum L.). International Journal of Plant Breeding and Genetics 1: 29-33.

Soratto, R.P.; C.A.C. Crusciol; G.S.A Castro; C.H.M Costa and J. Ferrari Neto (2012) Leaf application of silicic acid to white oat and wheat. R.Bras. Ci. Solo, 36 (5): 1538-1544.

Taiichiro Hattoria; Shinobu Inanagaa; Hideki Arakib; Ping Ana, Shigenori Moritac, Miroslava Luxova' d and Alexander Luxe (2005) Application of silicon enhanced drought tolerance in Sorghum bicolor physiologia Plantarum, 123: 459-466.

Taiz, L. and E. Zeiger (2006) Plant Physiology, 4th (Ed.). Sinauer Associates Inc. Publishers, Massachusetts, USA.

Torres-Rubio, M.G., S.A. Valencia-Plata, J. BernalCastillo and Martienez-Nieto, P. (2000) Isolation of Enterobacteria, Azotobacter sp. And Pseudomonas sp., Producers of Indole 3-Acetic Acid and Siderophores, from Colombian Rice Rhizosphere. R. L. De Microbiologiea, 42: 171-176.

Vanderlinde, E.M., J.J. Harrison, A. Muszynski, R.W. Carlson, R.J. Turner and C.K. Yost (2010) Identification of a novel $\mathrm{ABC}$-transporter required for desiccation tolerance, and biofilm formation in Rhizobium leguminosarumbv. viciae 3841. FEMS Microbiol. Ecol., 71: 327-340.

Venuprasad R., H.R. Lafitte and G.N. Atlin (2007) Response to direct selection for grain yield under drought stress in rice. Crop Sci. 47: 285-293.

Wolf, B. (1982) A comprehensive system of leaf analysis and its use for diagnosing crop nutrient status. Commun. Soil Sci. Plant Anal., 13: 10351059.

Yang, J., J.W. Kloepper and C.M. Ryu (2009) Rhizosphere bacteria help plants tolerate abiotic stress. Trends Plant Sci. 14: 1- 4.

Zahra, M.K. (1969) Studies of silicate bacteria. M.Sc. Thesis, Fac. Agric., Cairo Univ., Egypt, p:111.

(Received 20/12/2018; accepted 12/2/2019) 